\title{
Urban Environmental Stress and Behavioral Adaptation in Bhopal City of India
}

\author{
Parul Rishi ${ }^{1}$ and Gayatri Khuntia ${ }^{2}$ \\ ${ }^{1}$ Department of Management, National Institute of Technical Teachers' Training and Research, Bhopal 462002, India \\ ${ }^{2}$ Natural Resource Management, Indian Institute of Forest Management, Bhopal 462003, India
}

Correspondence should be addressed to Parul Rishi, rishiparul@rediffmail.com

Received 13 July 2012; Revised 22 November 2012; Accepted 4 December 2012

Academic Editor: César Ducruet

Copyright (C) 2012 P. Rishi and G. Khuntia. This is an open access article distributed under the Creative Commons Attribution License, which permits unrestricted use, distribution, and reproduction in any medium, provided the original work is properly cited.

\begin{abstract}
The study assessed the effect of the urban environmental stress on the subjective well-being of the people in Bhopal city of India. The objectives were to assess the perceived urban environmental stressors and to explore the coping strategies adopted by the people to combat the outcomes of Urban Environmental Stress. Perceived Urban Environmental stressors' Scale (UES) and Urban Hassle Index were administered. The findings indicated that though people described their city as pleasant, a high level of stress was still perceived and its major reasons were found to be noise, waste accumulation, polluted air with smoke, and unhealthy environment in slums. The outcome of research suggests that the city planners should give equal priority to the natural resources and environment by various pollution management interventions and proper city planning. It is crucial for the wellbeing of the human beings to lower down the effect of stressors, so that the life in the city can be livable and of good quality. This paper provided guidelines for other metropolitan cities too for developing Environmental Competence and for generating mass awareness about the Urban Environmental Stress and its possible management options to help people develop Environmental Resilience and functional coping.
\end{abstract}

\section{Introduction}

The globalization regime has led to an increase in income as well as, increase in poverty, inequalities, regional disparities, and above all environment stress of various types. Environmental problems and urban deterioration are the frequent result of shortcomings in the planning and urban management process, institutional frameworks and governance, and the inadequate allocation of financial resources in addressing environmental concerns. This dual trend of rapid population/economic growth is responsible for massive demographic shift from rural to urban societies raising enormous issues in terms of sustainability, efficiency, and equity measured in terms of environment sustainability index (ESI) and environment stress is one of its components [1].

1.1. Environmental Stress. Behavior is a function of the person, the environment, and the interaction between the two [2]. Therefore if the person's environment is not much acceptable then the person starts behaving in an undesirable manner which is reflected in the form of stress. It is originated by adverse environmental conditions interfering with normal human functioning and is considered as a threat full for today as well as for the future. In the city environment there exists a higher order of aversive situation like pollution, noise, overcrowding, extreme temperature, and the like which propel the person to behave in an indifferent way. Environmental stressors are typically aversive, primarily uncontrollable, and of variable duration and periodicity and require low to moderate adjustment [3]. Daily hassles are ones which include typical events of the traffic or the jam or the ordinary life that may cause frustration, tension, or irritation. The stress provided by the urban environment is often reflected in the form of physical turmoil, psychological illness, and reduced social interaction [4]. Studies on the effect of different environmental stressors on people indicate that they can impact people's behavior, mood, 


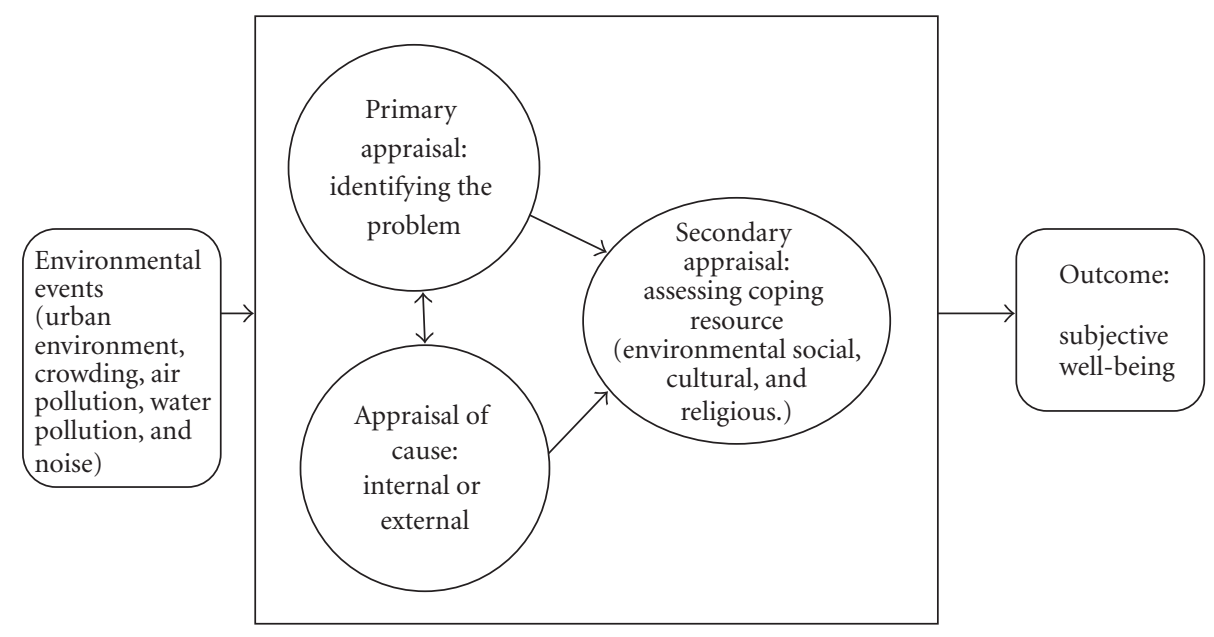

FIgURE 1: An Eclectic Model of UES and coping in relation to subjective well-being.

cognitive function, physical health, and/or psychological well-being.

To manage this it is necessary to develop and use interdisciplinary approaches that integrate biological, social, and other sciences to provide a better understanding of the challenges of land use planning and management $[5,6]$.

A model of stress representing the causes and consequences of UES is given in below (see Figure 1).

1.2. Urban Environmental Stress and Health (UES). Life in the urban settings is an interface between the adverse physical settings (which include pollution, high population, extreme temperature, crowding, degraded landscape, overaccumulation of solid waste, etc.) and individual characteristic arising by the time spent in the exposure to such aversive situation like time spent in commuting, time spend in crowd, exposure to polluted air and smokes, exposure to high level of noise, and so forth. If these situations are beyond the tolerance level, the person is said to be under stress. Urban environment stress is the situation that represents the level of anxiety of the urban inhabitants, facing the daily humdrum that are incompatible with their life [7]. Commuting as stressors, leads to consequences in the way it interferes with family and leisure activities and increased absenteeism from work. Costa et al. [8] shows that commuters generally experienced a more stressful life style, with increased psychological and physical health problems. Cities are the greater source of noise leading to greater level of annoyance, irritation, and insomnia. Several surveys have focused on residents' annoyance with traffic noise, sometimes so aversive as to discourage any type of social activity, including aggressive acts.

1.3. Coping with Environmental Stress. Coping is an important aspect of dealing with stress. Development of coping abilities that can make a person's personal adaptation successful is of importance as it can influence a person's selfconfidence and outlook in life. Coping for stress is either problem focused or emotion focused. In both cases, effective coping leads to a reappraisal in which the threat or damage is reduced. The role of coping influencing subjective well-being is represented in Figure 1 as above. Research has examined the degree to which various coping strategies impacts happiness and well-being. The positive affect associated with enhanced immune function is derived from many sources, including sensory pleasures, appreciating beauty, rewarding relationships, or involvement in intrinsically motivated activities through which one experiences a sense of mastery or self-determination [9]. Leisure activities are undertaken by a choice of activities like recreation, attending social gathering, and religious way or by some physical exercise. In order to overcome stress, people adopt to various types of coping such as social coping, environmental coping, religious coping, physical coping, and cultural coping, and so forth. There is an evidence that certain coping strategies, such as spirituality, positive reappraisal, optimism, and active problem solving are linked to higher subjective well-being $[10,11]$. Coping and adaptation have also been related to subjective well-being.

1.4. Subjective Well-Being. Subjective well-being (SWB) consists of people's own evaluations of their lives. WHO constituted well-being as "not merely the absence of disease or infirmity" but rather "a state of complete physical, mental and social well-being." Therefore it is essential for each individual to attain well-being for overall development. SWB is an umbrella term for the different valuations people make regarding their lives, the events happening to them, their body and mind, and the circumstances in which they live [12].

Cummins [13] has identified eight domains of Quality of Life (QOL) and well-being is one of its major focus. These include relationship with family and friends, emotional wellbeing, health, work and productive activity, material wellbeing, feeling part of one's local community, personal safety, and quality of environment. Improving well-being within this approach requires progressive satiation of hierarchical needs [14]. Within the hierarchy of human needs, the highest level is self-actualization, predicated on the attainment 
or fulfillment of the lower level needs. The ultimate need to which humans aspire is self-actualization and SWB is that stage of self-actualization where the human beings think of achieving well-being that is not materialistic [15]. Human well-being is mostly influenced by cultural ecosystem services referring to the aesthetic, spiritual, psychological, and other nonmaterial benefits that humans obtain while being in contact with ecosystems. Therefore achieving SWB is also a need that is the ultimate end of every individual which not only depends upon the economical factors but also to some extent on the external environmental factors.

1.5. Sustainability in Urban Life. The nature of modern urbanization may have deleterious consequences for mental health through the influence of ever increasing stressors and adverse life events, such as overcrowded and polluted environments, poverty and dependence on a cash economy, high levels of violence, and reduced social support [16]. Therefore while planning for a city enough amounts of natural settings should be kept to buffer the effect of pollutions (noise, air, and dust) and that will provide a sense of aesthetic beauty both for recreation and improving the quality of environment of the surroundings. Therefore, the promotion, maintenance, and preservation of publicly accessible green space can be regarded as an environmental sustainability.

In view of the above background of research, the study was conducted to assess the urban environmental stressors and coping strategies of Bhopal city dwellers and also to further explore the effect of above on subjective wellbeing. Information obtained from the above objective will be analyzed in context of the city profile to conduct the environmental appraisal of Bhopal and provide guidelines for other busy urban settlements for developing environmental Competence based on experience and results of the study. The paper also highlights various environmental issues of the city in order to recommend possible measures to improve the total quality of life in urban settlements from an environmental perspective.

\section{Methodology}

2.1. Study Area. The study was conducted in the comprehensive urban areas of Bhopal, the capital of the state of Madhya Pradesh, located at the central part of India on the Malwa plateau at $23.27^{\circ} \mathrm{N}$ and $77.4^{\circ} \mathrm{E}$ with the average elevation of 1637 feet. It is the second largest city in Madhya Pradesh and known as the City of Lakes as its landscape is dotted with a number of man-made as well as natural lakes. The city has uneven elevation and has small hills within its boundaries.

2.2. Sample. At the first stage, list of government, private, and business organizations, falling under each zone was collected. Organizations from each category were purposively selected from each zone based on their willingness to cooperate for the study. Final sample was selected from 33 organizations, representing gender and income categories.
From each organization about $8-10 \%$ of sample was randomly selected. The final sample consisted of 224 (male: 146; female: 78) respondents of working population aged 20-60 years (mean age: $35 \mathrm{yrs}$ ) selected from east, west, north, and south zones of Bhopal.

2.3. Tools and Techniques. As per the nature of the study, primary as well a secondary data was collected from different sources, that is, the individual respondents as well as the government organizations like State Pollution Control Board, Town and Country Planning Office, Environmental Planning and Coordination Organisation (EPCO), statistical census, and the concerned websites. For primary data collection, tools administered are given below.

2.4. Perceived Urban Environmental Stressors' Scale (UES). UES was designed by the investigators to assess the perceived urban environmental stressors of city dwellers. It has 19 items based on 4-point Likert type continuous rating scale. Various stressors were then classified under different categories like air, water, noise, waste management, and presence of slums. The Cronbach $\alpha$ of complete scale was found to be 0.83 .

Sample Item. I feel disturbed regarding degradation of my city's natural environment.

2.5. Urban Hassles of City Dwellers. To assess the types and level of different hassles which the working population in the city experiences, the urban hassle index [17] was adapted and expanded based on the types and categories of stressors specific to the urban environment of India as well as in discussion with people living in urban settings. Some of the hassels asked were traffic congestion, unmanageable garbage, expansion of slum areas, and so forth. Participants were asked to indicate how often the listed events have happened to them during the last few months on a four-point rating scale. Finally, people were required to rank the life at Bhopal as very stressful, stressful, not much stressful, pleasant, or very pleasant.

2.6. Subjective Well-being (SWB). SWB was assessed using the Satisfaction with Life Scale (SWLS) based on the scale of SWB developed by Diener and Larsen [18], to evaluate the appraisal about their life. It is recommended as a complement to scales that focus on psychopathology or emotional well-being because it assesses an individual's conscious evaluative judgment of his or her life by using the person's own criteria. The instrument is based on four items that inquire about respondents' overall assessment of their lives. Generally the cognitive appraisal involved in measuring life satisfaction is believed to require a comparison by individuals between the current status of their lives and selfdefined expectations regarding what they would like their lives to be. This comparison may be in relation to a selfdefined ideal, to other people, or to one's own past.

Sample Item. The quality of my surrounding environment is close to my ideal. 
2.7. Coping Scale. For the purpose of measuring the coping strategies, a scale was designed where the most commonly used coping strategies adopted by the respondents of the city were listed and respondents were asked to estimate their frequency of undertaking that activity for coping with stress on a four-point rating scale. Estimation was done to see the involvement of respondents for various recreational or other activities for coping with environmental stress.

Sample Items. Roaming in the nearby forest areas; meditation and relaxation; morning walk and exercise, and so forth.

2.8. Secondary Data Collection. Secondary data about the working population was collected from the Economic and Statistical Directorate of Madhya Pradesh. The pollution level data was collected from the State Pollution Control Board (SPCB), MP Regarding the physical data of the city and the presence of natural resources, data has been recorded from the Bhopal Developmental Plan obtained from the Town and Country Planning Office. The Environmental status Report of Bhopal (ESR, 2006, and ESR, 2000) was used to have a knowledge about the overall environmental condition of Bhopal. Besides, several other websites were also referred along with various maps of the city to have an idea about the zone wise different official establishments of the city.

\section{City Profile}

3.1. Urban Bhopal. Bhopal vies for an improved urban infrastructure aesthetically, environmentally, and physically in order to open the opportunities of investments into an already fast growing city of lakes. It had a first hand experience of one of the most heart wrenching environmental disasters of Union Carbide leak of 45 tons of poisonous methyl isocyanate gas 25 years ago. It was the stigma that has limited the city and the state to grow economically though the strong resilience on the part of people is able to partially overcome the same now. The city's economy is heavily reliant upon the markets of jewelry, electrical goods, cotton, and chemicals; however the gas leak terminated most of the Bhopali's tolerance for chemical industries. The most imminent trade of all is the art of handicraft. Bharat Heavy Electricals Ltd. (BHEL), which is the largest manufacturing and engineering enterprise in India, has its unit in Bhopal. The industrial suburb of Bhopal accommodates many plants belonging to some of the esteemed companies including Eicher, Crompton Greaves, Procter \& Gamble, Larsen \& Turbo, Fujitsu, and HEG. Some factors that make Bhopal an attractive prospect for investors are strategic geographic location, abundant and skilled man-power base, availability of cheap labor, availability of land at an affordable price, peaceful political scenario and, hence, peaceful law and order situation, vibrant industrial base, availability of rich and fertile land, and natural resources, and so forth. Apart from these, Bhopal has a well-developed industrial infrastructure that facilitates excellent interstate connectivity. Besides industrial base and public sector organizations, being the capital city, Bhopal is having a sizable population of government employees.

The population of Bhopal urban area was 1.5 million as per 2001 Census, and is expected to be about 3 million by 2021 at the growth rate of $30-35 \%$ in the current decade. The per capita income of Bhopal is INR 58,174 as against the state average of INR 32,222 and the national average of INR 60,349 . Bhopal is an environmentally sensitive city because of the hills and water bodies and has a unique ecological and geographical pattern. Due to the pressures of urbanization, the ecology of the region is disrupted on one hand and, on the other hand, the demands for conventional construction material and life styles are causing severe impact to the environmental fabric of the town.

3.2. Environmental Issues in the City. Being the capital of MP, the city dwellers still experience the environmental stress in spite of having good chunk of area under the vegetation zone as compared to the other capitals of the country which show more significant level of pollution.

3.3. Water. Most of the water bodies in and around Bhopal are presently under great environmental stress due to pollution from point and nonpoint sources, eutrophication, fast growth of aquatic macrophytes, enrichment of nutrients, and human encroachments. As a result of these, all the water bodies are gradually getting filled up leading towards eutrophication. Due to the joining of untreated domestic sewage, washing activities, and so forth, the water quality of these water bodies has deteriorated to a great extent thereby reducing the carrying capacity of the system. Data from several studies indicate the contamination of nitrate in the ground water of Bhopal. Organic enrichment of the lake through floral offerings, idol immersion, and decomposition of aquatic weeds are also the significant causes of its eutrophication. Besides parameter(s) like Faecal coliform, $\mathrm{pH}$, fluoride, and sulphate, as well as total hardness also rendered water unfit for domestic purposes. Studies indicate that the water quality of Upper Lake exceeds D.O (Dissolve Oxygen) indicating a presence of high amount of microbial organisms.

3.4. Air. In comparison to other metropolitans of India the air quality of Bhopal is good, but still the air quality status of major urban location is no better than the adjoining industrial areas, mainly because of increased use of automobile vehicles by rapidly increasing population. The combustion of fossil fuel and industrial processes are the principal sources of pollutants in urban and industrial areas. The standards for concentration of $\mathrm{SO}^{2}$ in industrial and residential areas are $80 \mu \mathrm{g} / \mathrm{m}^{3}$ and $60 \mu \mathrm{g} / \mathrm{m}^{3}$ respectively, and are within the safe limit. Similarly the level of $\mathrm{NO}^{2}$ is also within the permissible limit as the prescribed limits are $80 \mu \mathrm{g} / \mathrm{m}^{3}$ and $60 \mu \mathrm{g} / \mathrm{m}^{3}$ in industrial and residential areas. But the major concern is for SPM and RSPM where value exceeded the stipulated limit. The standards prescribed for RSPM are $120 \mu \mathrm{g} / \mathrm{m}^{3}$ for industrial area and $60 \mu \mathrm{g} / \mathrm{m}^{3}$ for residential area. A research study of the World Health Organization shows air pollution 
with particulate matter claims an average of 8.6 months from the life of every person in the European Union [19] resulting in increased misery and panic and decreased well-being of the people.

The traffic movement has tremendously increased in the city (3142/hr, 2006 ESR). The vehicular growth has registered annual growth rate of $13.6 \%$ during the last eight years and the number of vehicles have nearly doubled from $1,30,317$ in 1991 to $2,59,171$ in 1999 . Now this figure must have reached to a very high level indicating a simultaneous increase in the pollution level. It is estimated that total vehicular pollution load in Bhopal city is $326.2 \mathrm{MT}$ per day, contributed by both diesel and petrol vehicles in the ratio of $7 \%$ and $93 \%$, respectively. Out of total pollution load of 326.2 tones per day, the major constituent is Carbon Monoxide with quantity of 215.6 tones per day followed by Hydrocarbons 92.1 tones per day and NOx 13.6 tones per day. The Light Tonnage Vehicles (LTV), including two wheelers were found contributing $84.4 \%$ of total pollution load, that is, 275.2 tones per day. The Heavy Tonnage Vehicles (HTV) are responsible for emitting large quantities of NOx. Ninety percent of $\mathrm{SO}^{2}$ emissions were found due to HTV and MTV. Increase in the level of the suspended matter increases the risk to lungs and makes them prone to respiratory diseases like pulmonary bronchitis, asthma, and so forth. The above level of pollutants load show that there is a great risk to the well-being of the citizens of Bhopal due to the excessive contaminants.

3.5. Noise. High noise levels are deleterious to human beings as well as animals. Under the noise level monitoring programme by MPPCB the noise level of 10 major cities were monitored in the year 2002-03 out of which Bhopal was on the top where $90 \%$ of the value exceed the limits indicating noise pollution in the city. Maximum noise level to which the residents in residential locality were exposed during night time was as high as $85.2 \mathrm{~dB}(\mathrm{~A})$ in south Bhopal area. Similarly, in a silence zone, the maximum noise to which the inmates of the north zone of Bhopal were exposed was as high as $86.6 \mathrm{~dB}(\mathrm{~A})$ during day time. Among the commercial areas, west zone was found to be noisy and the people living in surrounding areas were exposed to very high noise up to $101 \mathrm{~dB}$ (A) during day time. In the institutional areas also, noise level was found to be high. These values of noise were compared with the standards prescribed for specific areas which are illustrated in Table 1.

\section{Results}

To describe the city environment of Bhopal, various environmental situations were taken into account like traffic congestion, vehicular emission, congested habitat, expansion in slum, and so forth. to represent various problems that the citizens residing in Bhopal were experiencing. Response percentages of each category were calculated as mentioned in Figure 2.

Figure 2 shows that expansion of slums, unmanageable garbage, and traffic congestion were found to be some of the
TABLe 1: Permissible limits of noise at various locations.

\begin{tabular}{|l|c|c|}
\hline \multicolumn{1}{|c|}{ Area } & $\begin{array}{c}\text { Noise level } \\
\text { limits in } \mathrm{dB}(\text { day } \\
6 \mathrm{am}-9 \mathrm{pm})\end{array}$ & $\begin{array}{c}\text { Noise level } \\
\text { limits in } \mathrm{dB}(\text { day } \\
6 \mathrm{am}-9 \mathrm{pm})\end{array}$ \\
\hline Industrial & 75 & 70 \\
\hline Commercial & 65 & 55 \\
\hline Residential & 55 & 45 \\
\hline Sensitive & 50 & 40 \\
\hline
\end{tabular}

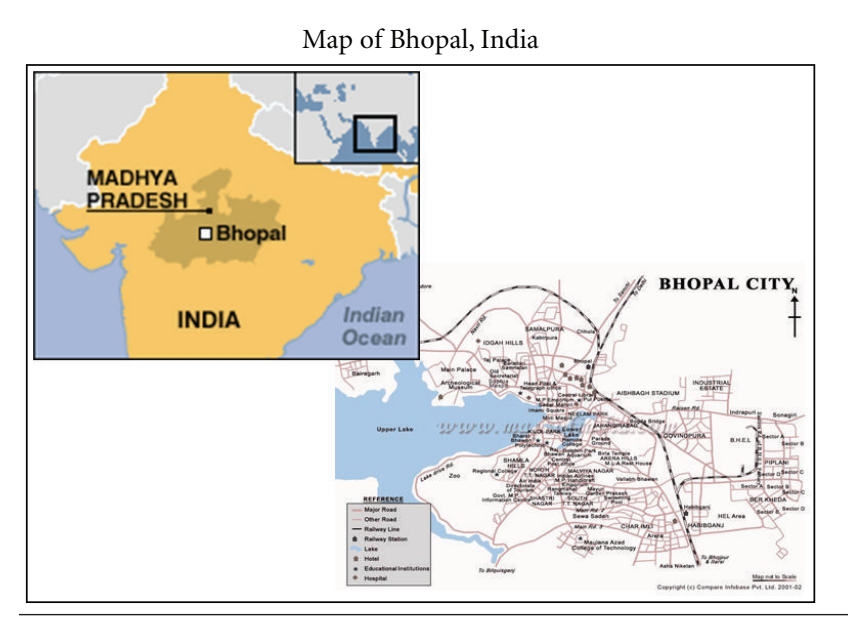

major problems in the city environment of Bhopal. A high level of perceived stress in the west zone was found followed by east, north, and south zones. The two indicators taken under the quality of air include polluted air and vehicular emission. There was a significant difference in stress found across zones due to the quality of air.

Perceived stress, when analyzed across gender, indicated that female respondents perceived more stress in comparison to their male counterparts. (mean: male: 3.00; female: 3.22; $F: 4.005, P<0.05)$ Regarding quality of air, it may be due to the higher sensitivity of women to the quality of air or relatively lesser exposure to commuting due to prevalent social practices.

When the overall assessment of Bhopal city was taken in order to assess the perceived UES, it was found that the highest percentage of people perceives Bhopal as not much stressful. Very few people perceived Bhopal as very stressful or very pleasant (Figure 3). This is due to the reason that when people compare Bhopal with other cities, the level of environmental condition is not perceived as much limiting due to available natural resources.

Coping strategies popularly adopted by the people were divided into five categories, namely, environmental coping, cultural coping, social coping, religious coping, and physical coping. Overall the scores of coping were found to be quite low as compared to the level of stress. However, the average coping score was more in the west zone as the level of stress was also high and coping was required to buffer the aversive impact of stress.

Significant mean differences were found in coping strategies across the zones (mean: east zone: 1.79; west: 2.06; north: 1.73; south: 1.48; F: 4.13, $P<0.05$ ). Social coping was found 


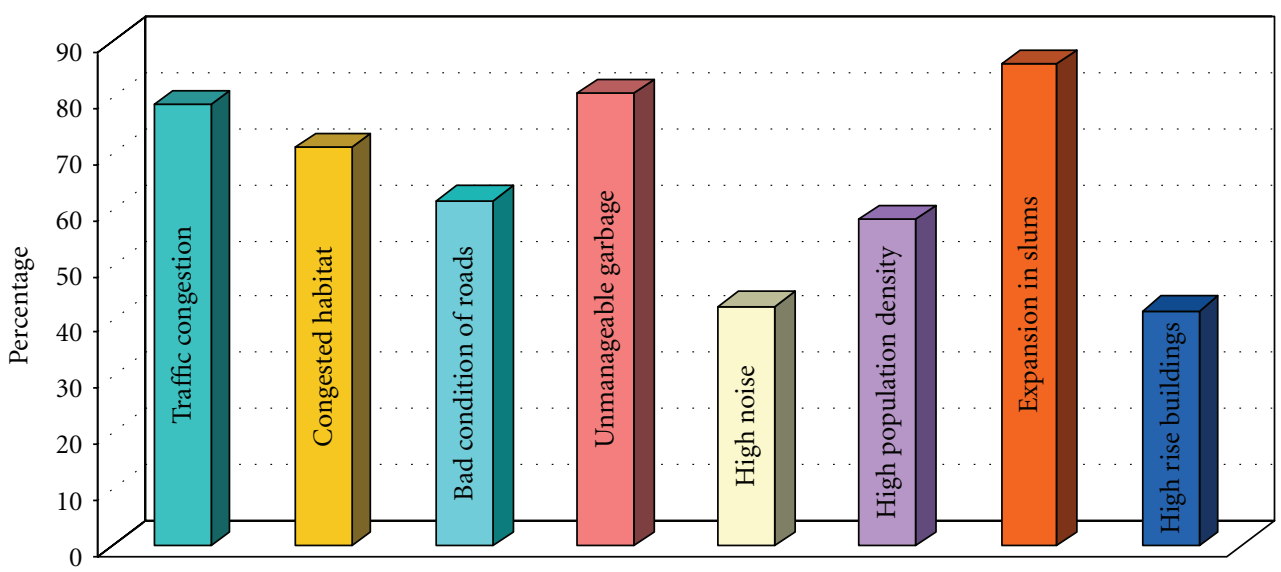

FIGURE 2: Major problems in Bhopal urban settlement.

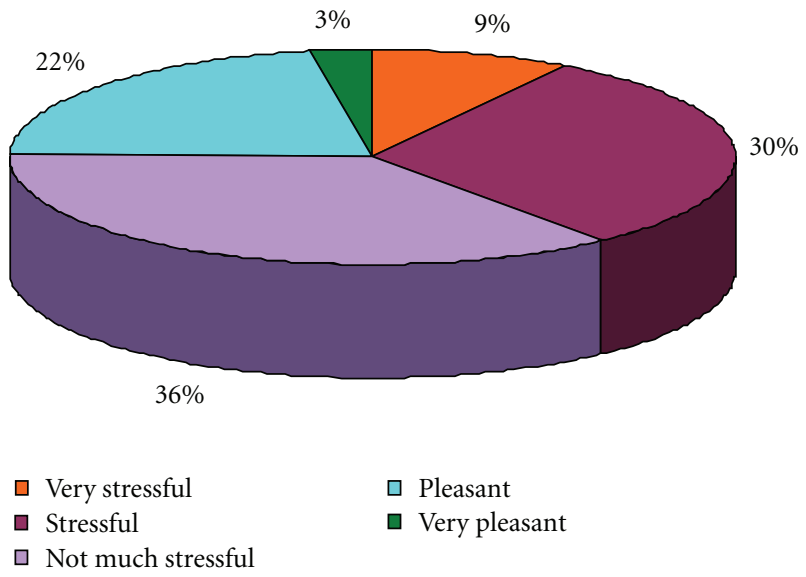

Figure 3: Life in the Urban settlement of Bhopal as Perceived by Residents.

to be most frequently adopted way of releasing stress by all the sample groups. ANOVA revealed no significant variance in cultural coping across the zones and gender; however the frequency of coping through physical activity was low to moderate.

The above analysis indicated highly significant differences in the mean values of stress and coping (mean: stress: 2.98; coping: 1.27; paired $t$ : $40.525, P<0.0001$ ) represented in Figure 4. This signified that though people were having a high level of stress still they were not adopting coping strategies the way they should do. It may be due to the adaptation to stressors and increased level of their resistance.

Assessment of environmental SWB was done by taking various indicators like quality of life, condition of urban living, satisfaction with surrounding environmental condition, satisfaction from domain city, and so forth. No significant differences in SWB across zones and gender were observed. Effect of urban environmental stress on coping and subjective well being was studied using Pearson's correlation and no significant correlation could be found between them (Figure 4). However, significant differences in the means of

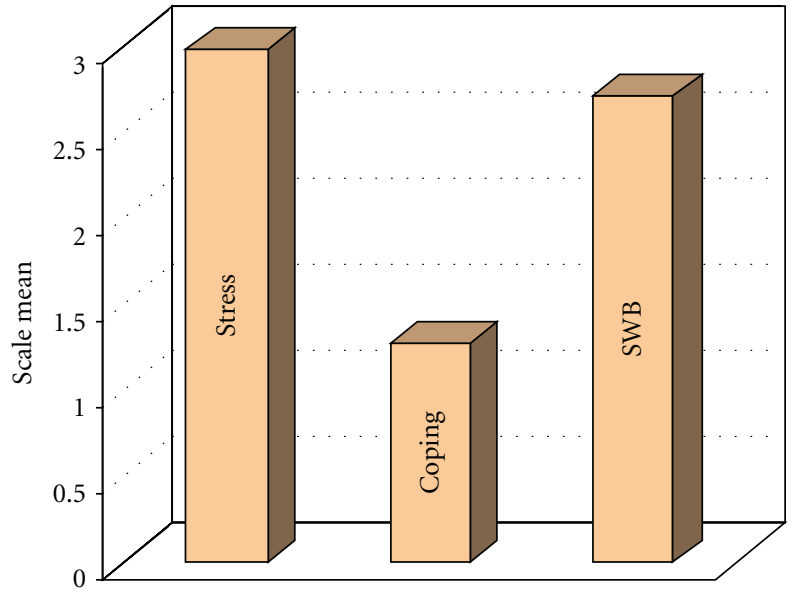

FIGURe 4: Perceived levels of stress coping and SWB in Bhopal urban settlement.

stress and SWB were observed (mean: stress: 2.98; SWB: 2.71; $(t: 4.397, P<0.0001))$. The reason of high SWB despite stress can be explained on the basis of strong social bonding in the community expressed through high social coping which acts as a buffer to negative effects of stress and increases the SWB. Correspondingly there was a significant difference in the mean of SWB and coping (mean: coping: 1.27; SWB: 2.71 $(t: 26.431, P<0.0001))$.

\section{Discussion}

Findings indicated that citizens of Bhopal perceived various kinds of environmental stressors, though the level of stress varied across occupations and zones of residence. The major problem perceived by the people was found to be unhealthy environment in slums as, despite being the capital city, there were no proper arrangements for slum dwellers which forced them to lead unwholesome life in the city causing stress to the citizens.

Experience of stress differs across zone as urbanization has not taken place in all the zones in a uniform manner. 
Well-developed infrastructures, ample supply of water, and parks for recreation are mostly located in the south zone though some parks are there in the north zone. The south zone which is commonly known as new Bhopal is surrounded by urban forest which reduces the stress level of the working class people to a great extent. It has been seen that woodland and green space can contribute to people's health and well-being. Residents living in buildings without nearby trees and grass reported more procrastination in facing their major issues and assessed their issues as more severe, less soluble, and more long-standing than did their counterparts living in greener surroundings [20]. According to the researchers, green spaces benefit health by encouraging local residents to undertake physical activities, such as walking or sports. There is also evidence that being in green environments can reduce blood pressure and relieve stress. While not everyone has equal access to green spaces, those who do have access tend to use them, regardless of socioeconomic status [21]. The components of a green infrastructure could contribute to ecosystem health in urban and peri-urban habitats in order to increase the overall vegetation cover (natural, seminatural, and artificial), thus contributing to conservation of biological diversity [22]. Furthermore, it also maintains the integrity of habitat systems and may provide the physical basis for ecological networks. Only a few empirical studies have shown the successful role of ecological corridors asconduits for wildlife (e.g., [23]). So, the functionality of corridors in ecological networks remains contested $[24,25]$. However, in the absence of alternative strategies for addressing the ecological impact of fragmentation, ecological networks have become a popular element of urban planning [26] to relieve UES.

The study also highlighted the need to intervene in both design and social features of residential areas to promote mental well-being. Chronic exposure to environmental stressors that are uncontrollable may also produce greater susceptibility to learned helplessness [27]. People cannot predict or assert control over an environmental source of stress, but they learn that they have little ability to influence environmental outcomes by their behavior. Despite of high noise level in the north zone, people do not perceive any stress. This is because the reappraisal of the threat occurs where upon an aversive condition that was initially critically viewed becomes reappraised as minor problem or threat. Guite [28] conducted the study to examine the strength of the association between physical and social factors in the built environment and mental well-being. The most important factors that operate independently were neighbour noise, sense of overcrowding in the home, and escape facilities such as green spaces and community facilities, and fear of crime.

Analysis of results also found that people of the north zone do not perceive much stress despite of having large numbers of slums in those areas but people belonging to other zones perceived more stress due to slums. The reason behind that is adaptation level theory which predicts that immediate or previous exposure to high density of some dimension will cause a habituation process; wherein current judgments of the intensity of that dimension will be lowered relative to judgments by others without exposure to that dimension $[29,30]$. Therefore though there are higher numbers of slums in the north zone, people have developed adaptation to those surroundings therefore they no more perceive high stress like the other zones.

When the coping strategies were analyzed across the zone and gender it was found that social coping was the most preferred and personalized mode of coping among all the classes of people. Stress is also reduced by the availability of social support; in fact, social support may also ameliorate the physical symptoms of illness and enhance survival. Therefore, regardless of availability of time and resources all the people go for social coping. Findings indicate that women have a greater preference for social coping in comparison to other strategies indicating the greater involvement of women in social activities. Relaxing activities, especially visiting a park or walking under woodland, allow people the opportunity to meet others and extend their social network. The working class people of Bhopal do a moderate level of physical coping which is the most personalized method after social coping. Therefore meeting and interacting under the woodland motivated by social needs keep up the involvement in outdoor activities on the long term [31]. However, the benefit from physical coping provides people a buffer to reduce stress and provides a higher quality of life, enhances mood, reduces stress, and develops a more positive selfimage [32]. While commuting across the road side planted area people reduce their stress to some extent.

Despite of the high perceived stress it has been found that overall coping indices were low. Inability to cope raises level of arousal of people resulting in possible after effects like neurotic disorders, learned helplessness, performance deficit and so forth. Therefore, in this way the feedback turns back to perception of environment as more stressful. In all the classes of people coping behavior was less which makes the perception towards their environment as more stressful. The effect of UES and SWB is represented diagrammatically in Figure 5.

\section{Conclusions and Recommendations}

The study explored various environmental stressors as perceived by the working city dwellers of Bhopal and found high levels of perceived stress along with low coping indices differing across city zones and gender and making environmental perception further stressful but still a feeling of subjective well-being was found. Physical quality of environment and levels of pollution also varied across zones as urbanization had not taken place in the whole of the city in uniform manner. Recommendations for achieving sustainability of positive city environment to be implemented at macro-as well as microlevel were made.

At the macrolevel while planning for the city, a provision for low cost multistoried accommodation of slums dwellers was recommended, taking care of basics aesthetics, and amenities for slums dwellers to improve their quality of life and reduce the stress experienced by them and the others who get affected by their unhygienic living. In a followup, urban settlement of Bhopal pioneered in removing more 


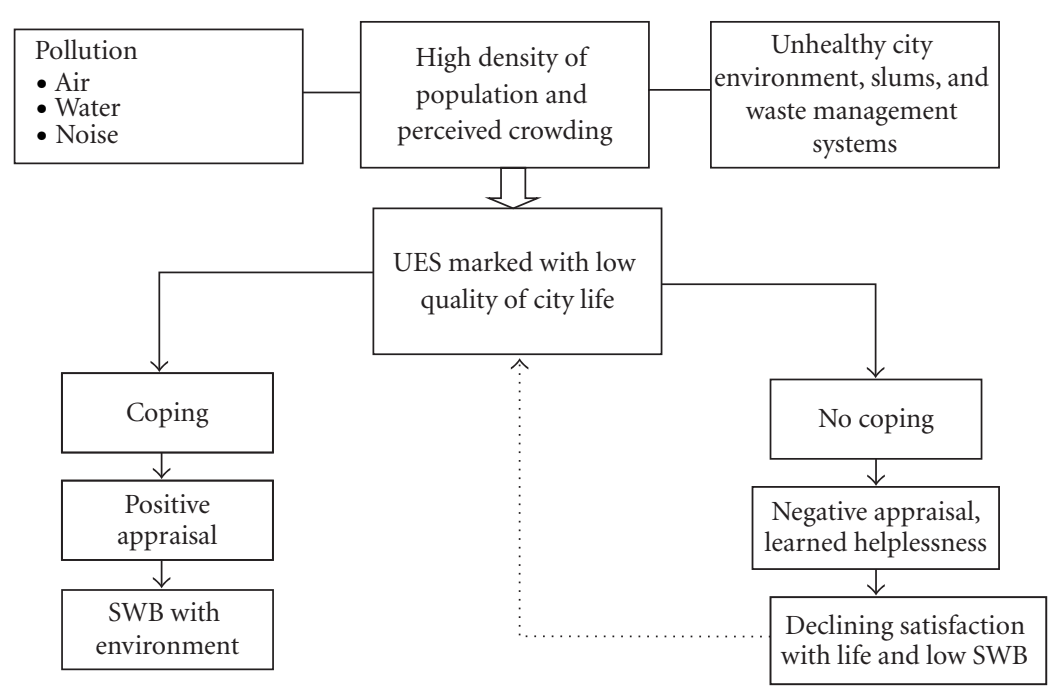

Figure 5: Effect of urban environmental stress on subjective well-being.

than $60 \%$ of the slums within the time frame of three years and converted them into multistory low cost housing apartments.

The east zone of Bhopal is an industrial hub, therefore while planning industries due attention should be given for enough plantation area with natural covering and recreation site to buffer the effect of pollution and stress. The State Pollution Control Board should more strictly ensure the abatement of rules by the industries. In the north zone, where there was a high level of air and noise pollution, the road side plantation can act as barrier to obstruct the air and noise pollution by plantation of trees. Hoardings at various recreation sites indicating the sensitivity of that area and threat to that area due to littering and disposables were also suggested, to generate awareness among the public.

Hassles of city life are indispensable; therefore promoting positive environmental appraisal through media to develop a sense of belongingness with the city was recommended. High internal locus of control is instrumental in this regard to reduce the effect of stress by effective coping. There is a need to further strengthen the social support system by maintaining healthy neighborhood and close interactions with family and friends to improve one's quality of life.

SWB is the ultimate aim of every individual; hence it is very important to focus on the surrounding natural environment which is an important indicator of quality of life. This study can provide a portrait of life in an urban scenario where, beside the financial matters, the role of other behavioral and environmental factors has also been studied. Finally the partnership to include environmental and behavioral professionals with local authority is important and a key to restore and improve the city environment of Bhopal urban settlement for positive environment appraisal and high subjective well-being. Outcome of this study would also be used for generating mass awareness about the urban environmental stress (UES) and its possible management options in the cities which will help the people to develop environmental resilience and functional coping to improve the subjective well-being of the people city dwellers.

\section{Acknowledgment}

This paper is a part of M. Phil dissertation of the second author supervised by the first author at the Indian Institute of Forest Management, Bhopal. Earlier version of this paper was presented in the 7 th International Conference on urban health at Vancouver, Canada, in September 2008.

\section{References}

[1] A. de Sherbinin, "The role of sustainability indicators as a tool for assessing territorial environmental competitiveness," in Presented at the International Forum for Rural Development, pp. 1-16, Brasilia, Brazil, November 2003.

[2] K. Lewin, Field Theory in Social Science, Harper, New York, NY, USA, 1951.

[3] J. Campbell, "Ambient stressors," Environment and Behavior, vol. 15 , pp. 55-380, 1983.

[4] R. G. Barker, Concepts \& Methods for Studying the Environment of Human Behaviour, Ecological Psychology, Stanford University Press, Stanford, Calif, USA, 1968.

[5] F. Berkes and C. Folke, Eds., Linking Sociological and Ecological Systems: Management Practices and Social Mechanisms for Building Resilience, Cambridge University Press, New York, NY, USA, 1998.

[6] R. Haeuber and P. Ringold, "Ecology, the social sciences and environmental policy," Ecological Applications, vol. 8, no. 2, pp. 330-331, 1998.

[7] M. Pacione, "Urban environmental quality and human wellbeing-a social geographical perspective," Landscape and Urban Planning, vol. 65, no. 1-2, pp. 19-30, 2003.

[8] G. Costa, L. Pickup, and V. Di Martino, "Commuting-a further stress factor for working people: evidence from the European Community. II. An empirical study," International Archives of Occupational \& Environmental Health, vol. 60, no. 5, pp. 377-385, 1988. 
[9] C. Charnetski and F. Brennan, Feeling Good Is Good for You, Rodale Press, 2001.

[10] E. Diener, E. M. Suh, R. E. Lucas, and H. L. Smith, "Subjective well-being: three decades of progress," Psychological Bulletin, vol. 125, no. 2, pp. 276-302, 1999.

[11] S. Folkman, "Positive psychological states and coping with severe stress," Social Science and Medicine, vol. 45, no. 8, pp. 1207-1221, 1997.

[12] R. Veenhoven, "Wellbeing in the welfare state: level not higher, distribution not more equitable," Journal of Comparive Policy Analysis, vol. 2, pp. 91-125, 2000.

[13] R. A. Cummins, "The domains of life satisfaction: an attempt to order chaos," Social Indicators Research, vol. 38, no. 3, pp. 303-328, 1996.

[14] A. Maslow, The Farther Reaches of the Human Mind, Viking Press, New York, NY, USA, 1970.

[15] M. Clarke, "Assessing well-being using hierarchical needs, wider Institute for Development Economics Research," Research paper no. 2005/22, 2005.

[16] R. Desjarlais, L. Eisenberg, B. Good, and A. Kleinman, World Mental Health: Problems and Priorities in Low-Income Countries, Oxford University Press, New York, NY, USA, 1995.

[17] D. B. Miller, S. E. Webster, and R. MacIntosh, "What's there and what's not: measuring daily hassles in urban African American adolescents," Research on Social Work Practice, vol. 12, no. 3, pp. 375-388, 2002.

[18] E. Diener and R. J. Larsen, "The experience of emotional wellbeing," in Handbook of Emotions, M. Lewis and J. M. Haviland, Eds., pp. 405-415, 1993.

[19] WHO, "Particulate Matter Air Pollution: how it harms health," 2005, http://www.euro.who.int.

[20] F. E. Kuo, "Coping with poverty: impacts of environment and attention in the inner city," Environment and Behavior, vol. 33, no. 1, pp. 5-34, 2001.

[21] R. Mitchell and F. Popham, "Effect of exposure to natural environment on health inequalities: an observational population study," The Lancet, vol. 372, no. 9650, pp. 1655-1660, 2008.

[22] E. J. Mutran, M. Danis, K. A. Bratton, S. Sudha, and L. Hanson, "Attitudes of the critically ill toward prolonging life: the role of social support," The Gerontologist, vol. 37, no. 2, pp. 192-199, 1997.

[23] N. M. Haddad and J. J. Tewksbury, "Low-quality habitat corridors as movement conduits for two butterfly species," Ecological Applications, vol. 15, no. 1, pp. 250-257, 2005.

[24] R. F. Noss, "Sustainable forestry or sustainable forests?" in Defining Sustainable Forestry, G. H. Aplet, N. Johnson, J. T. Olson, and V. A. Sample, Eds., pp. 17-43, Island Press, Washington, DC, USA, 1993.

[25] P. Beier and R. F. Noss, "Do habitat corridors provide connectivity?" Conservation Biology, vol. 12, no. 6, pp. 12411252, 1998.

[26] R. H. G. Jongman and G. Pungetti, Eds., Ecological Networks and Greenways: Concept, Design, Implementation, Cambridge University Press, 2004.

[27] M. E. Seligman, Helplessness, Freeman, San Francisco, Calif, USA, 1975.

[28] H. F. Guite, C. Clark, and G. Ackrill, "The impact of the physical and urban environment on mental well-being," Public Health, vol. 120, no. 12, pp. 1117-1126, 2006.

[29] H. Helson, Adaptation-Level Theory, Harper, New York, NY, USA, 1964.

[30] J. F. Wohlwill, "Human adaptation to levels of environmental stimulation," Human Ecology, vol. 2, no. 2, pp. 127-147, 1974.
[31] R. Putnam, Bowling Alone: The Collapse and Revival of American Community, Simon and Schuter, New York, NY, USA, 2000.

[32] B. G. Berger, "Psychological benefits of an active lifestyle: what we know and what we need to know," Quest, vol. 48, no. 3, pp. 350-353, 1996. 


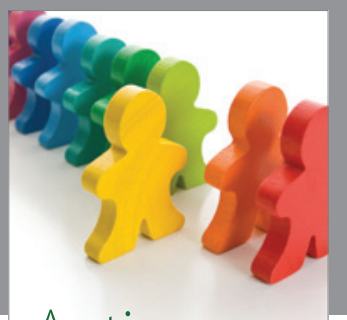

Autism

Research and Treatment
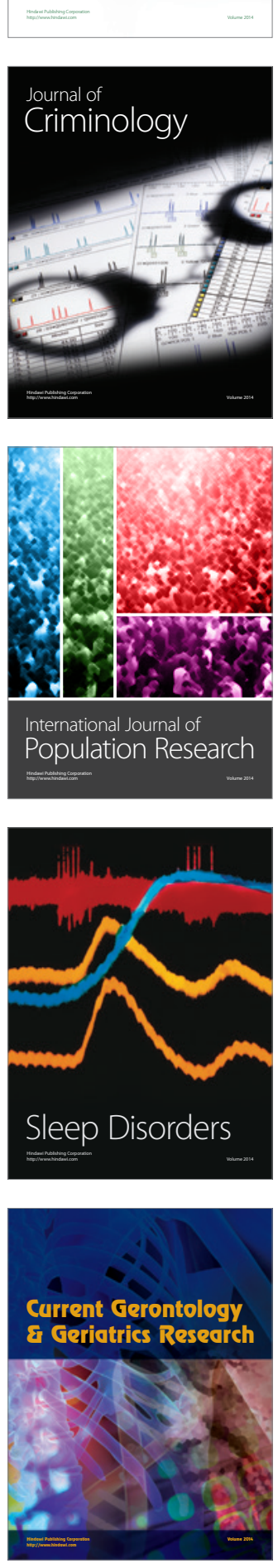
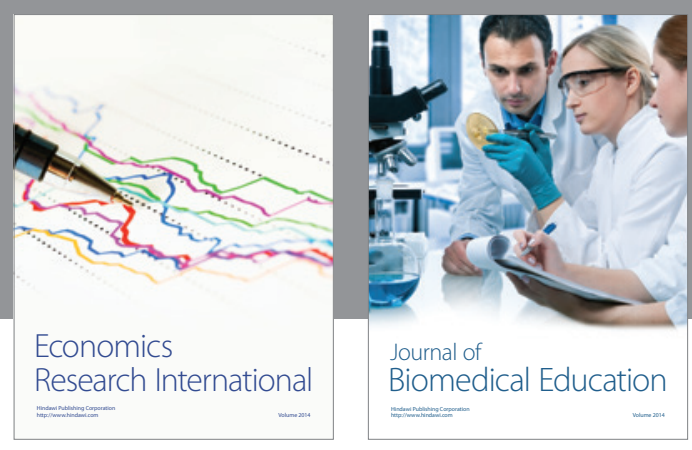

Journal of

Biomedical Education

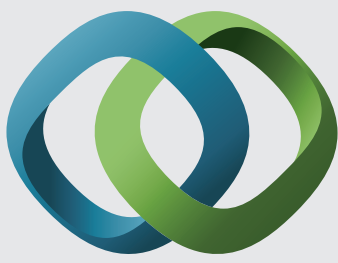

\section{Hindawi}

Submit your manuscripts at

http://www.hindawi.com
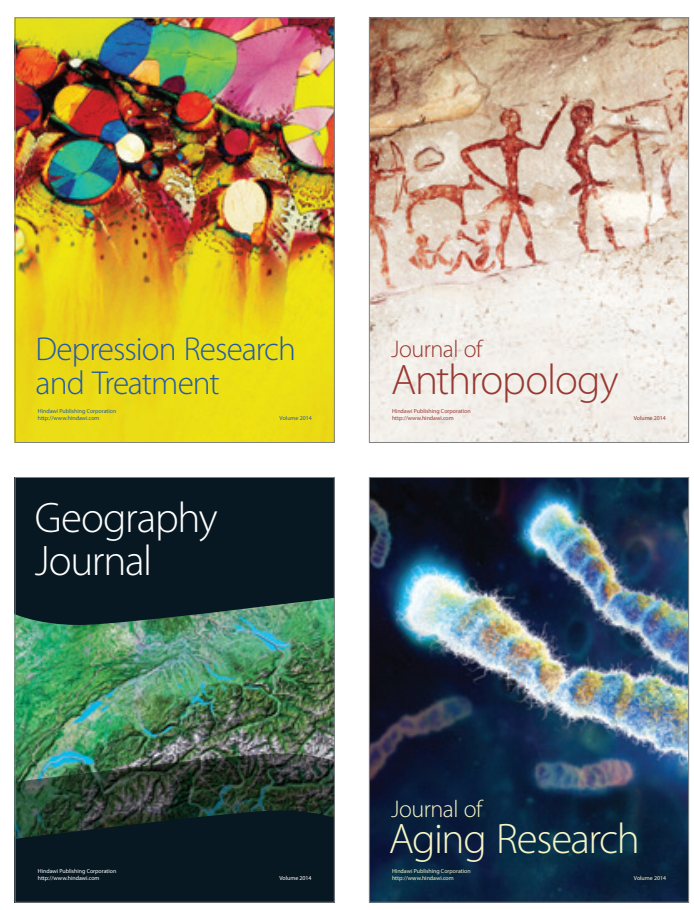

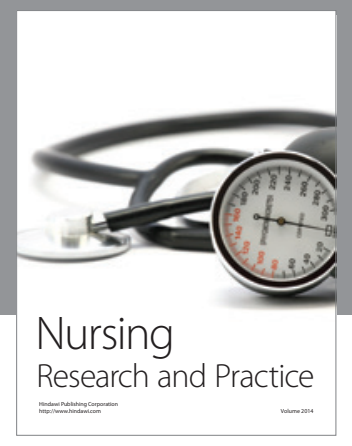

Nursing

Research and Practice

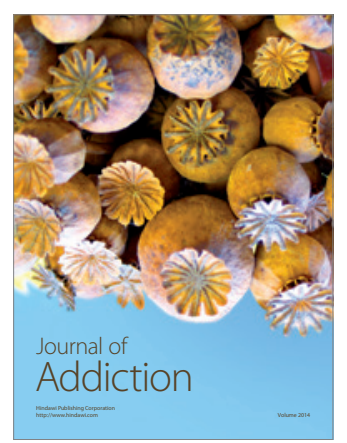

Child Development

Research

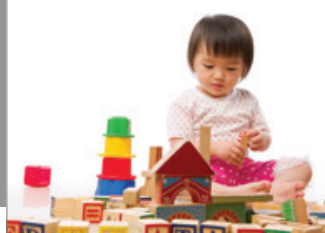

迥
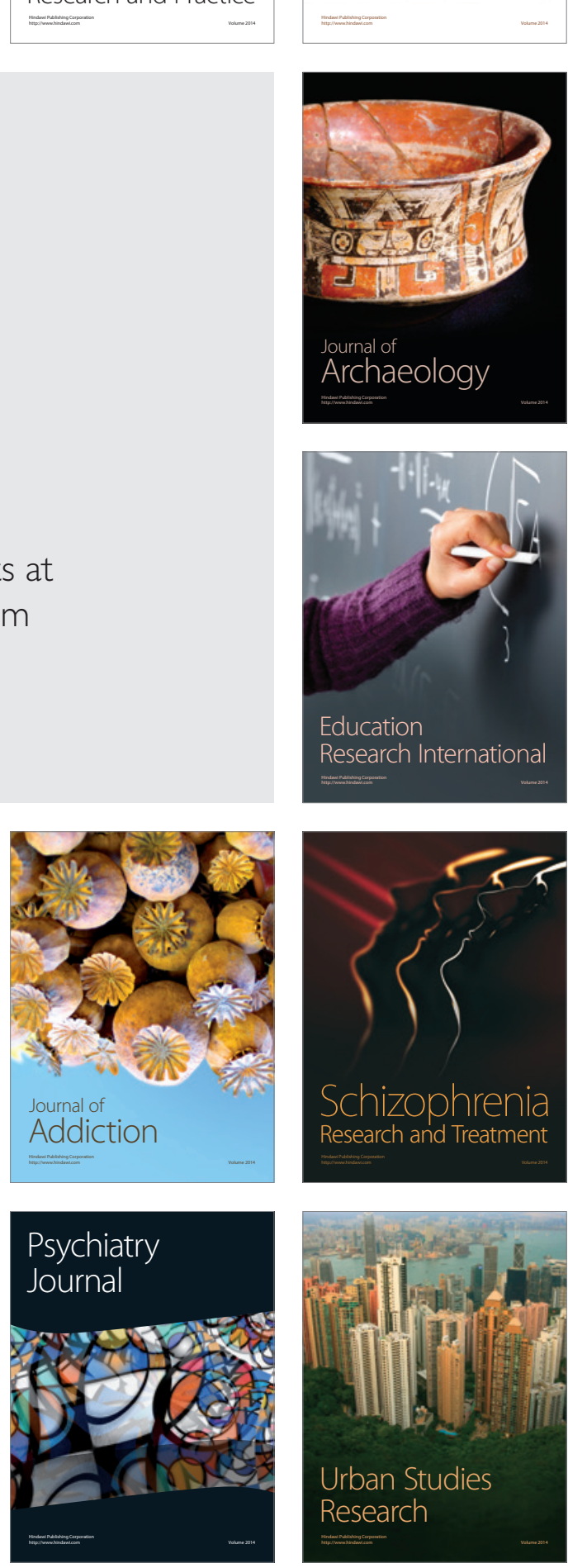